\title{
PROJETO DE REQUALIFICAÇÃO URBANA E PAISAGÍSTICA DO CANTEIRO CENTRAL DA AVENIDA AFONSO PENA, LAGOA VERMELHA-RS
}

\author{
URBAN AND LANDSCAPE RENOVATION OF AVENIDA AFONSO PENA, LAGOA VERMELHA-RS
}

MELO, Evanisa F. R. Quevedo.

Engenheira florestal, agrônoma e professora Msc. da Faculdade de Engenharia e Arquitetura, Universidade de Passo Fundo.

E-mail: evanisa@upf.brou5590@upf.br

ROMANINI, Anicoli

FIORI, Sibele

FORCELINI, Eveli Ballen

NORRO, Julio Ariel Guigou

\section{RESUMO}

A avenida Afonso Pena destaca-se por ser o coração da cidade de Lagoa Vermelha, RS. Nela desenvolvem-se diversas atividades inerentes aos vários setores da comunidade. Ao longo da via encontra-se o comércio local, clubes de recreação, bancos, a prefeitura e residências unifamiliar e multifamiliares. Aliado a isso a via é utilizada como ponto de encontro da população. Assim, com o intuito de melhorias para esses canteiros consolidou-se o Projeto de Requalificação Urbana e Paisagística do Canteiro Central da Avenida Afonso Pena, Lagoa Vermelha-RS, iniciou-se a parceria do Núcleo de Arquitetura, Desenvolvimento Urbano e Comunitário (NADUC - Projeto de Extensão Comunitário), Setor de Urbanismo, da Universidade de Passo Fundo (UPF), juntamente com a prefeitura de Lagoa Vermelha. O trabalho foi iniciado com o reconhecimento da situação atual dos canteiros centrais da avenida Afonso Pena, através de análises da infra-estrutura e da arborização, além da aplicação de dois questionários a população da cidade. Foram analisadas as seguintes situações: identificação das espécies existentes e introduzidas, situação fitossanitária das espécies e situação ambiental das áreas verdes localizadas, no canteiro central, para então, acontecer à proposta urbana e paisagística do local.

Palavras-chave: Requalificação urbana e paisagística, planejamento urbano, arborização urbana.

\begin{abstract}
The avenue Afonso Pena is distinguished for being the heart of the city of Lagoa Vermelha, RS. In develops diverse inherent activities to the some sectors of the community. To the long one of the way the commerce meets local, clubs of recreation, banks, the multifamiliar city hall and residences unifamiliar and. Ally to this the way is used as point of meeting of the population. Thus, with the intention of improvements for these seedbeds the Project of Urbana Requalification was consolidated and Paisagística of the Central Seedbed of the Avenue Afonso Pena, Lagoa Vermelha-RS, initiated it partnership of the Nucleus of Architecture, Urban and Communitarian Development (NADUC - Communitarian Project of Extension), Sector of Urbanism, the University of Passo Fundo (UPF), together with the Municipal City hall of Lagoa Vermelha. The work was initiated with the recognition of the current situation of the seedbeds central offices of the avenue Afonso Pena, through analyses of the infrastructure and the arborization, beyond the application of two questionnaires the population of the city. The following situations had been analyzed: identification of the existing and introduced species, fitossanitária situation of the species and ambient situation of the located green areas, in the central seedbed, for then, to happen to the proposal urban and paisagística of the place.
\end{abstract}

Key words: Urban and landscape requalification, urban planning, urban arborization. 
A história de Lagoa Vermelha, como de tantos outros municípios gaúchos, surgiu em função do trânsito das tropas que, no século XVII, eram conduzidas a São Paulo. A colonização inicial recebeu influência de tropeiros de Laguna, Lapa, Curitiba e São Paulo. Como se tratava de um cruzamento de estradas - uma vinha das Missões e a outra de Santa Catarina - houve, também participação dos jesuítas. Um dos caminhos dos tropeiros paulistas passava junto a um local preferido para descanso, já que junto ao mesmo havia uma lagoa onde o gado matava a sede. A coloração das águas dessa lagoa inspiraria a denominação dada ao povoado que ali surgiu. Em 1842 se fixaram os primeiros moradores, e em 10 de maio de 1881 se emancipa definitivamente.

Localizada na região dos Campos de Cima da Serra, o município de Lagoa Vermelha-a "cidade da amizade" - é conhecida como um dos maiores destaques na produção de maçãs. Lagoa Vermelha tem sua economia baseada na agricultura, pecuária e na industrialização de hortigranjeiros e laticínios. Suas principais atividades econômicas são agricultura, fruticultura, pecuária, indústria moveleira e comércio. Possui 28.786 habitantes, clima temperado e está a $805 \mathrm{~m}$ do nível do mar. A temperatura média anual é de $16^{\circ} \mathrm{C}$ variando entre $36^{\circ}$ e $3^{\circ} \mathrm{C}$ negativos (CUNHA, 1997).

A avenida Afonso Pena destaca-se por ser o coração da cidade de Lagoa Vermelha, RS, pois nela desenvolvem-se diversas atividades inerentes aos vários setores da comunidade. Ao longo da via encontra-se o comércio local, clubes de recreação, bancos, a prefeitura e residências unifamiliar e multifamiliares. Aliado a isso a via é utilizada como ponto de encontro da população (Figura 1).

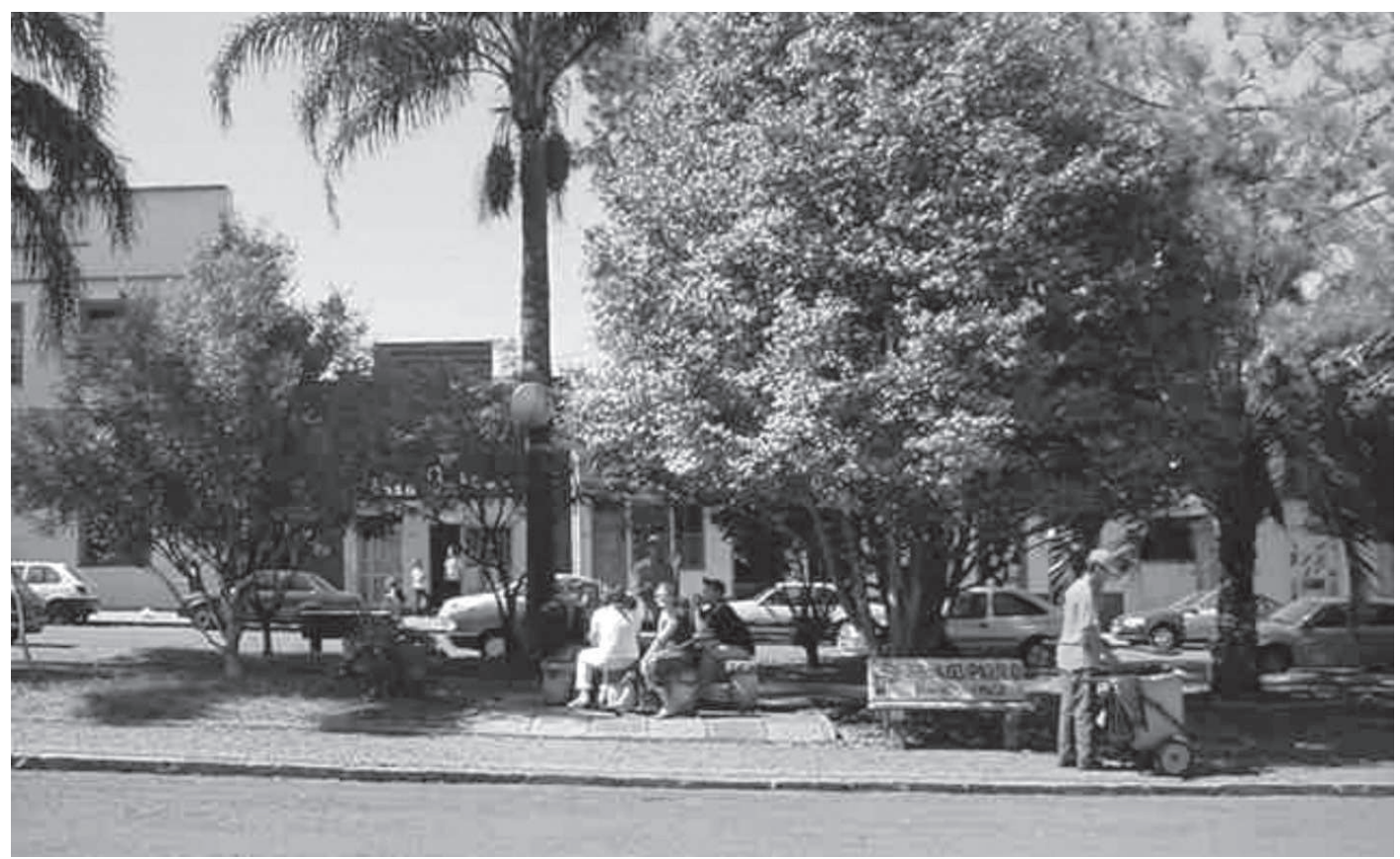

Figura 1: Canteiro da avenida Afonso Pena

Fonte: Autores

Assim, como projeto de extensão, iniciou-se a parceria do Núcleo de Arquitetura, Desenvolvimento Urbano e Comunitário (NADUC), Setor de Urbanismo, da Universidade de Passo Fundo (UPF), juntamente com a prefeitura de Lagoa Vermelha, no desenvolvimento do Projeto de Requalificação Urbana e Paisagística do Canteiro Central da avenida Afonso Pena, Lagoa Vermelha-RS.

O trabalho foi iniciado com o reconhecimento da situação atual dos canteiros centrais da avenida Afonso Pena, Lagoa Vermelha, através de análises da infra-estrutura e da arborização, além da aplicação de dois questionários a população da cidade. 
Foi feito um inventário semelhante ao realizado por Milano (1987) da vegetação existente na avenida Afonso Pena, Lagoa Vermelha, RS, identificando (LONGHI, 1995; LORENZI, 1992; REITZ et al, 1988) e localizando as espécies nos seus respectivos espaços. Foi retirada uma amostra (exsicatas) para identificação e arquivamento, a fim de ser documentada e permitir o intercâmbio, sendo um exemplar arquivado no herbário da Universidade de Passo Fundo (RSPF).

Foram analisadas as seguintes situações: identificação das espécies existentes e introduzidas, situação fitossanitária das espécies e situação ambiental das áreas verdes localizadas, no canteiro central da avenida Afonso Pena. Foram inventariados 559 exemplares de 68 espécies arbóreas, observando-se a existência de dois períodos distintos de desenvolvimento da cidade, caracterizado pelo uso de espécies arbóreas nativas e exóticas. Os representantes das espécies exóticas de maior ocorrência são pinus (Pinus sp), ciprestes (Cupressus sp), extremosas (Lagertroemia indica), ligustros (Ligustrum japonicum), tuias (Thyja sp.) e tipuanas (Tipuana tipu). Destacam-se pelo porte, beleza e colorido de suas flores espécies nativas como os ipês (Tabebuia sp), canafístula (Peltophorum dubium), falso-barbatimão (Cassia leptophylla), gerivá (Syagrus romanzoffiana), timbaúva (Enterolobium contortisiliquum), butiazeiro (Butia capitata), cedro (Cedrella fissilis), guajuvira (Patagonola americana), entre outras.

O canteiro central da avenida Afonso Pena (Figura 2), apresenta uma vegetação exuberante, densa e colorida, transformando-o num espaço agradável para a comunidade em geral. A revitalização dessa área procura compatibilizar o crescimento da cidade, sua história e a vegetação, com a manutenção de espaços e modos de vida tradicionais do município em uma área de 23.370,80 $\mathrm{m}^{2}$, com seus monumentos, igreja, edificações e marcos históricos, de forma a atender as necessidades dos usuários e a vocação do lugar de modo sustentável. Dentro deste perímetro, a intervenção será conduzida segundo três enfoques diferenciados: o da preservação ambiental, o da reconstituição e o da renovação urbana. Princípios estes que nortearam o projeto do Corredor Cultural do Rio de Janeiro (SIMÕES JÚNIOR, 1994).

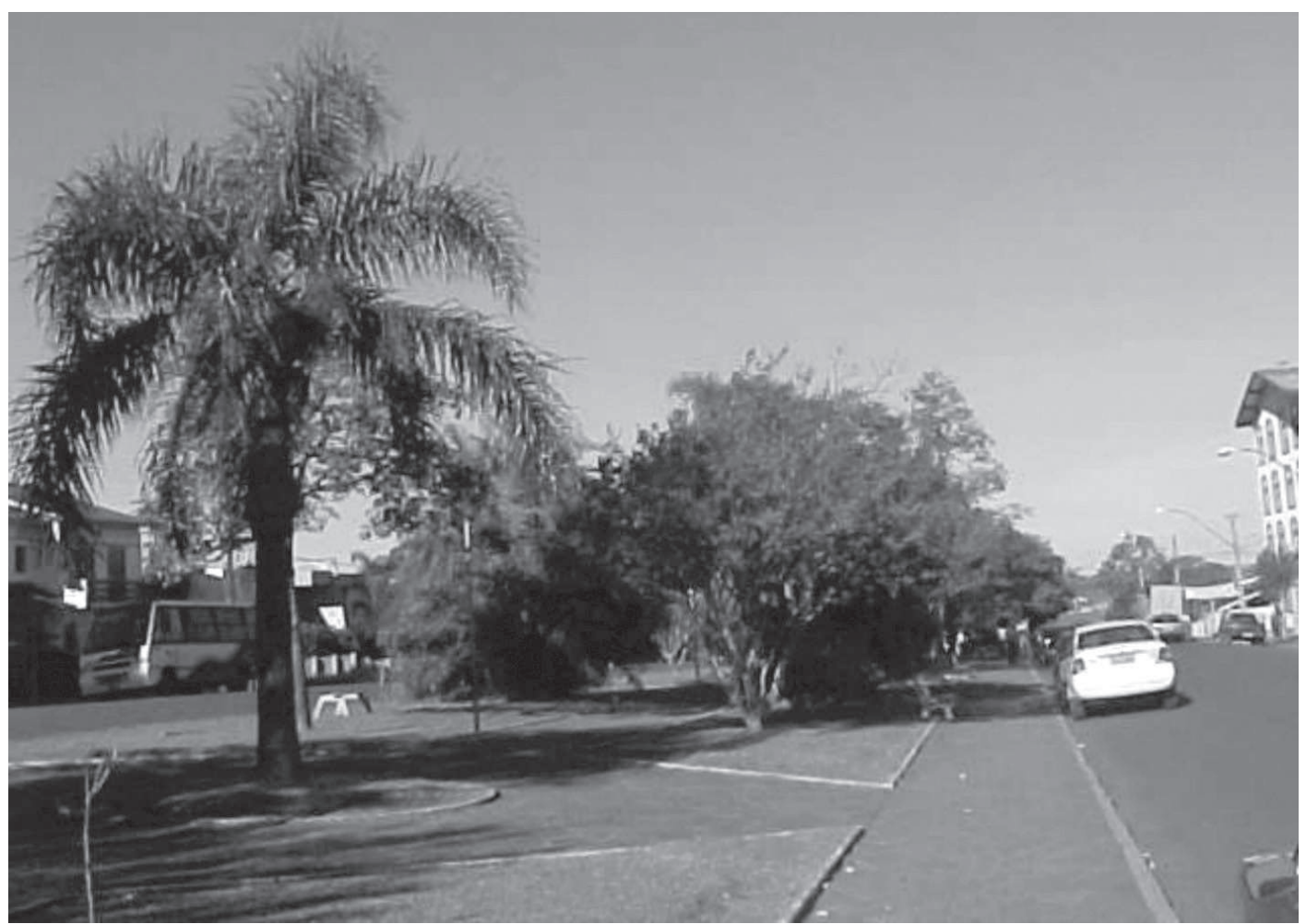

Figura 2: Canteiro da avenida Afonso Pena com a vegetação existente Fonte: Autores 
Com o reconhecimento físico da área verificou-se que avenida é constituída de quinze canteiros centrais, os quais foram divididos em setores (Figura 3) para uma melhor compreensão da

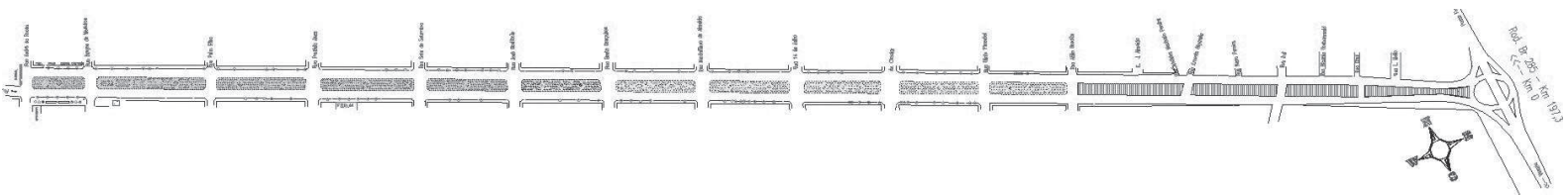

LEGENDA:

$\square$ Setor 01

Setor 02

Figura 3; Planta Baixa avenida Afonso Pena

$\square$ Setor 03

Fonte: Prefeitura de Lagoa Vermelha.

área de estudo, através da análise visual da avenida observou-se a existência de três períodos distintos de desenvolvimento da cidade:

- Setor 1: Canteiros próximos a prefeitura, com estrutura física em razoável estado de conservação, a vegetação com a incidência de espécies nativas e exóticas (Figura 4), sendo as exóticas exemplares com maior porte, indicando terem sido as primeiras a fazerem parte da arborização urbana, inseridas provavelmente sob influência dos aspectos culturais de seus colonizadores. Os ciprestes (Cupressus sp), representam 62\% do total da vegetação do canteiro 4 (Figura 5) e apresentam alguns exemplares com problemas fitossanitários. Essa densidade de ciprestes não permite o desenvolvimento de outras espécies vegetais prejudicando a inserção de cores. Questões estas que apontam a necessidade de redução do uso de ciprestes na composição arbórea dos canteiros, além da questão alérgica desta espécie.

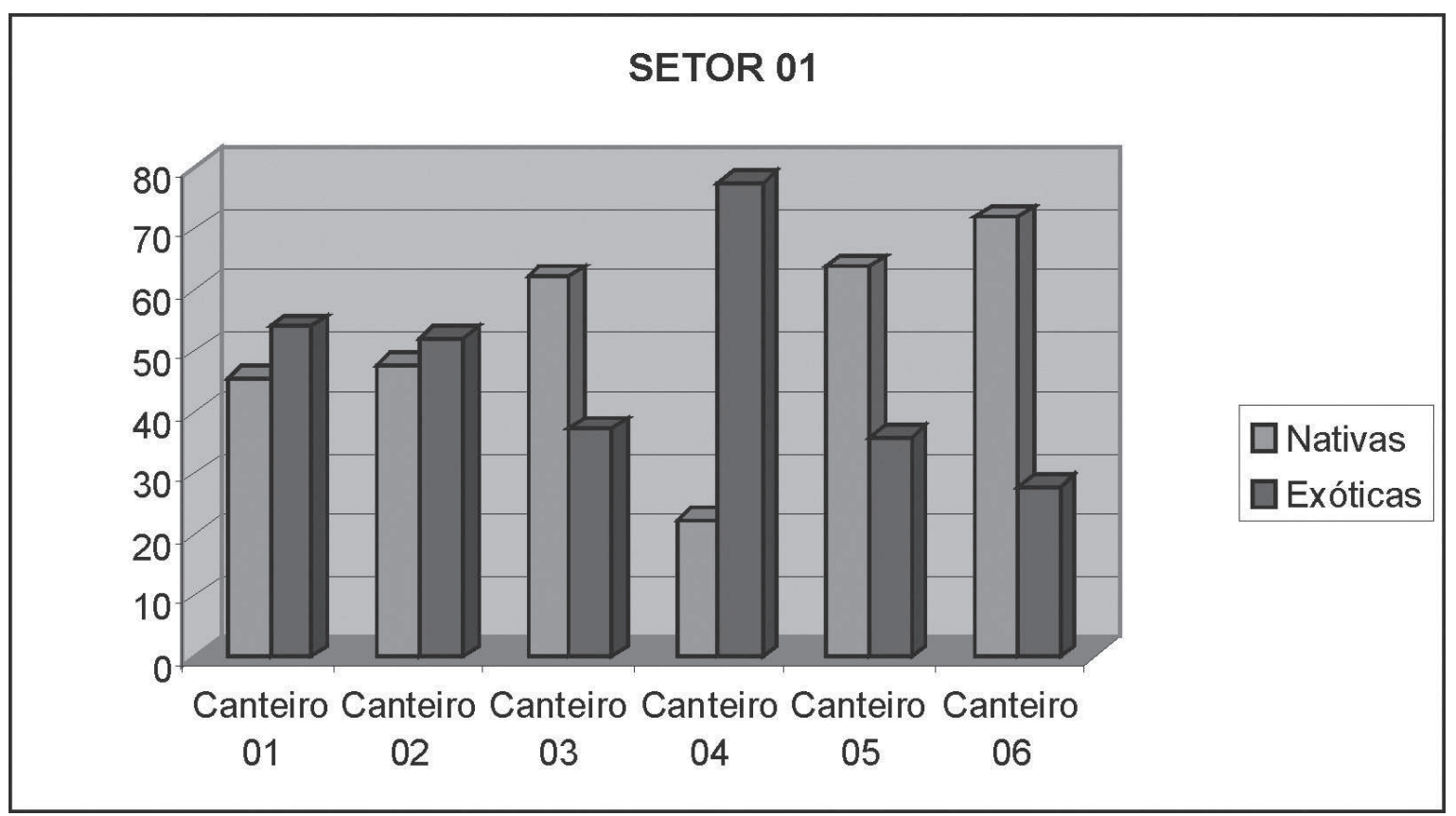

Figura 4: Espécies nativas e exóticas que compõe o Setor 1 da avenida Afonso Pena, Lagoa Vermelha, RS, 2003 Fonte: Autores

- Setor 2: Canteiros centrais, com estrutura física bastante comprometida de uma forma geral, com exceção do canteiro localizado em frente ao posto de gasolina que foi reformulado, a arborização, compõe-se por árvores nativas (Figura 6), porém com uma maior diversidade de espécies. Por se tratar de uma área urbana e de uso público, busca-se o enriquecimento da flora nativa, sua preservação e conservação. Verifica-se uma grande concentração de ligustros (Ligustrum japonicum) apenas no canteiro 11 (Figura 7), espécie considerada alergógena. 


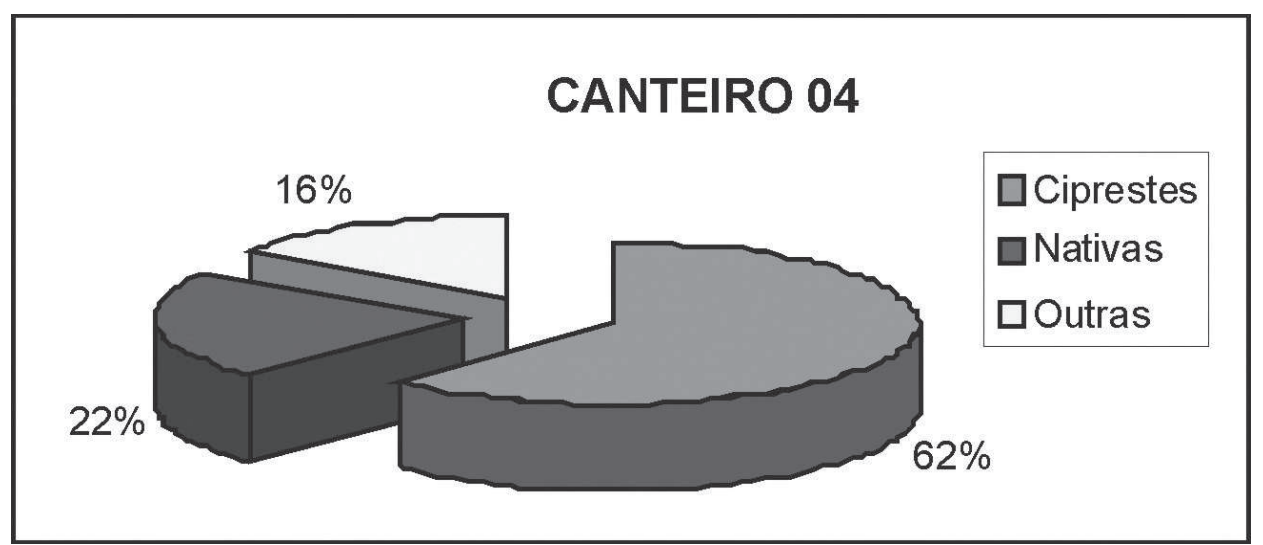

Figura 5: Predominância dos ciprestes no canteiro 4 - Setor 1 da avenida Afonso Pena, Lagoa Vermelha, RS, 2003

Fonte: Autores

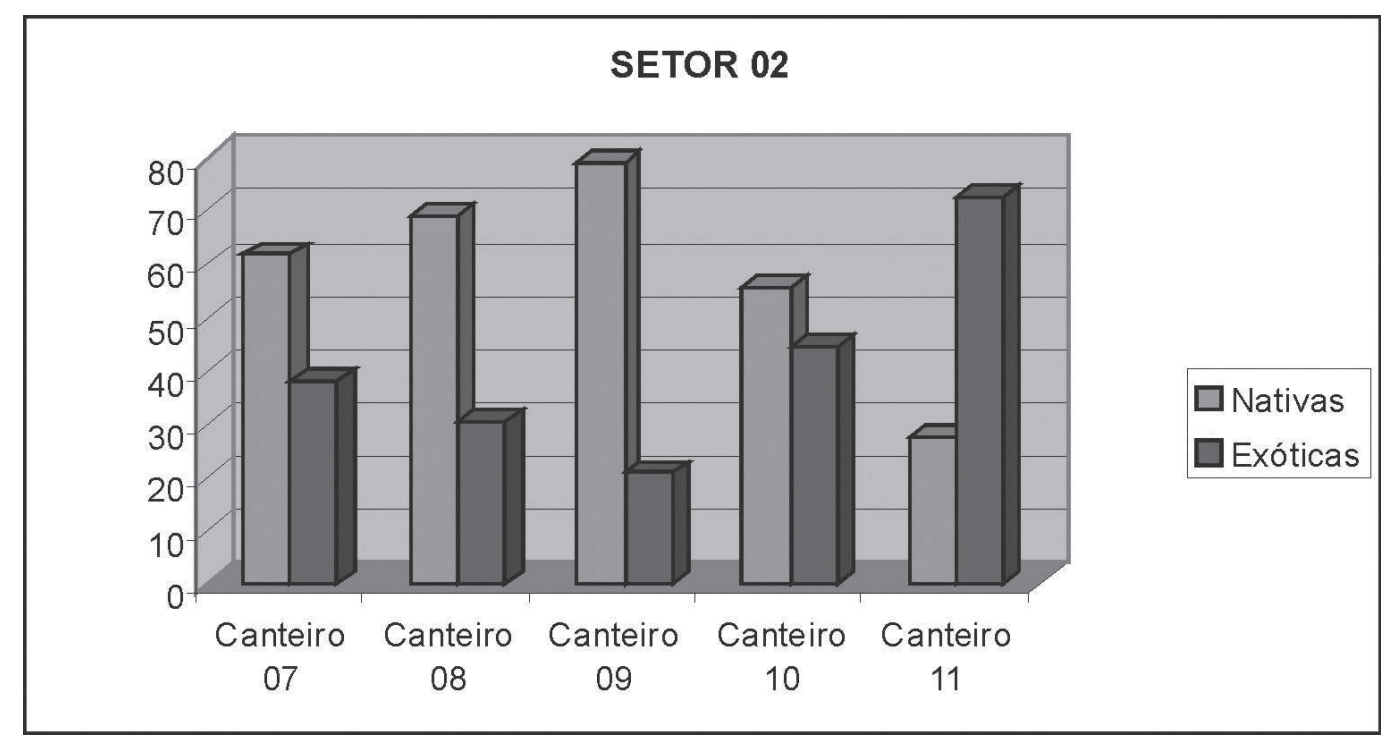

Figura 6: Porcentagem de espécies nativas e exóticas - Setor 1 da avenida Afonso Pena, Lagoa Vermelha, RS, 2003

Fonte: Autores

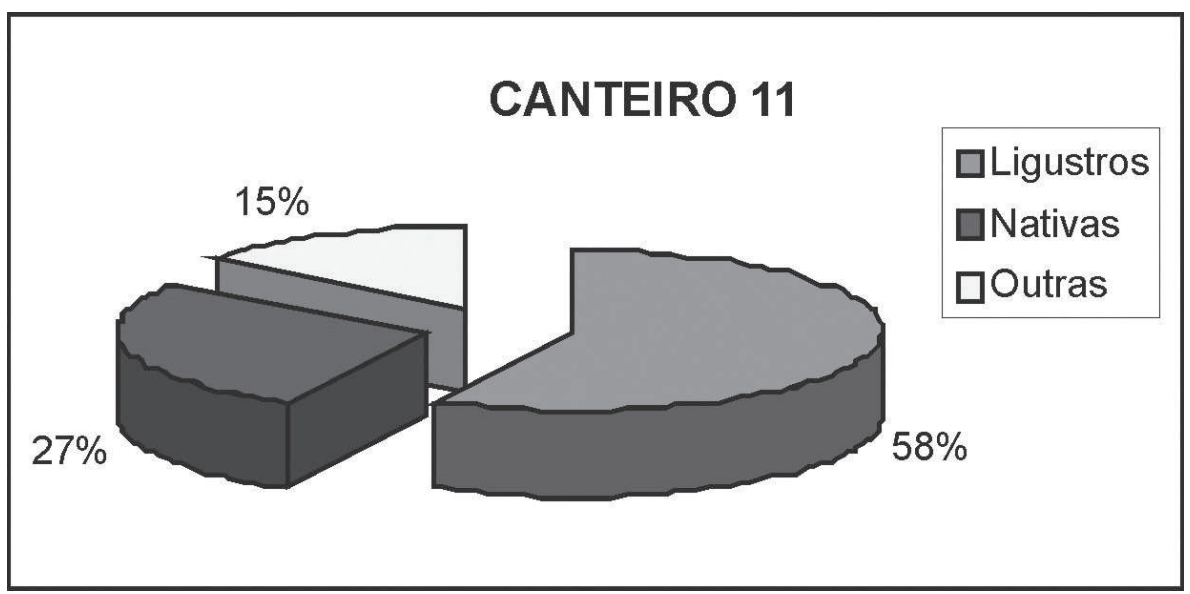

Figura 7: Predominância de ligustros no canteiro 11 - Setor 2 da avenida Afonso Pena, Lagoa Vermelha, RS, 2003

Fonte: Autores 
- Setor 3: Canteiros próximos ao trevo de acesso à cidade, compostos por uma área carente de infra-estrutura e vegetação (Figura 8), portanto realizou-se um trabalho de caracterização da área através da implantação de árvores nativas, espécies já utilizadas nos demais canteiros, conferindo uma unidade a avenida Afonso Pena, bem como, uma variedade de cores nas diferentes estações do ano.

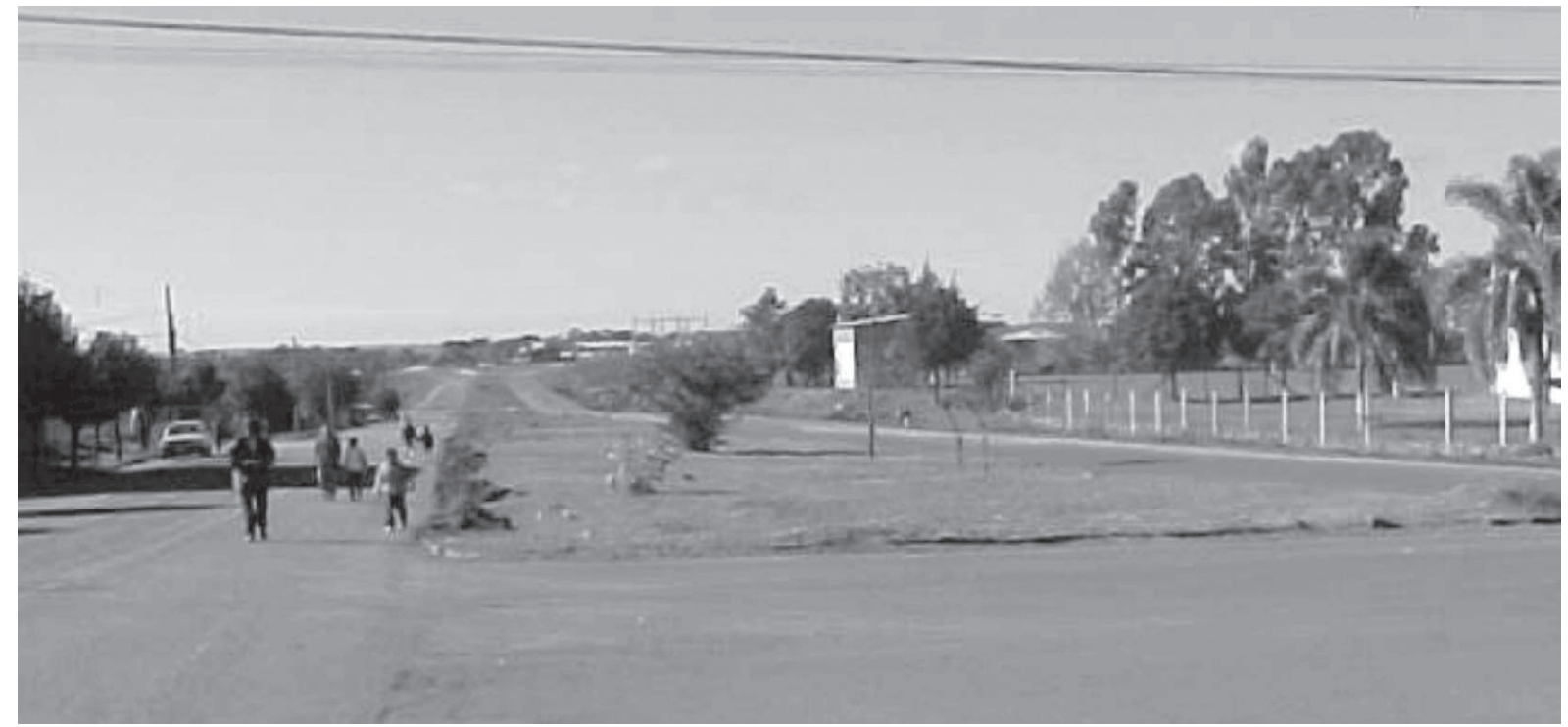

Figura 8: Aspecto geral do Setor 3 da avenida Afonso Pena, Lagoa Vermelha, RS, 2003

Fonte: Autores

A análise indica que há uma predominância de espécies nativas nos canteiros da avenida (Figura 9), porém a área central é composta basicamente por espécies exóticas, enquanto que os canteiros das áreas recém urbanizadas compõem-se por espécies arbóreas nativas. Observase que a implantação ocorreu sem estudo prévio da arborização, sendo necessário realizar planejamento e monitoramento das espécies vegetais de forma a contribuir para a qualidade visual do ambiente construído em relação ao meio ambiente proporcionando maior conforto ambiental da área.

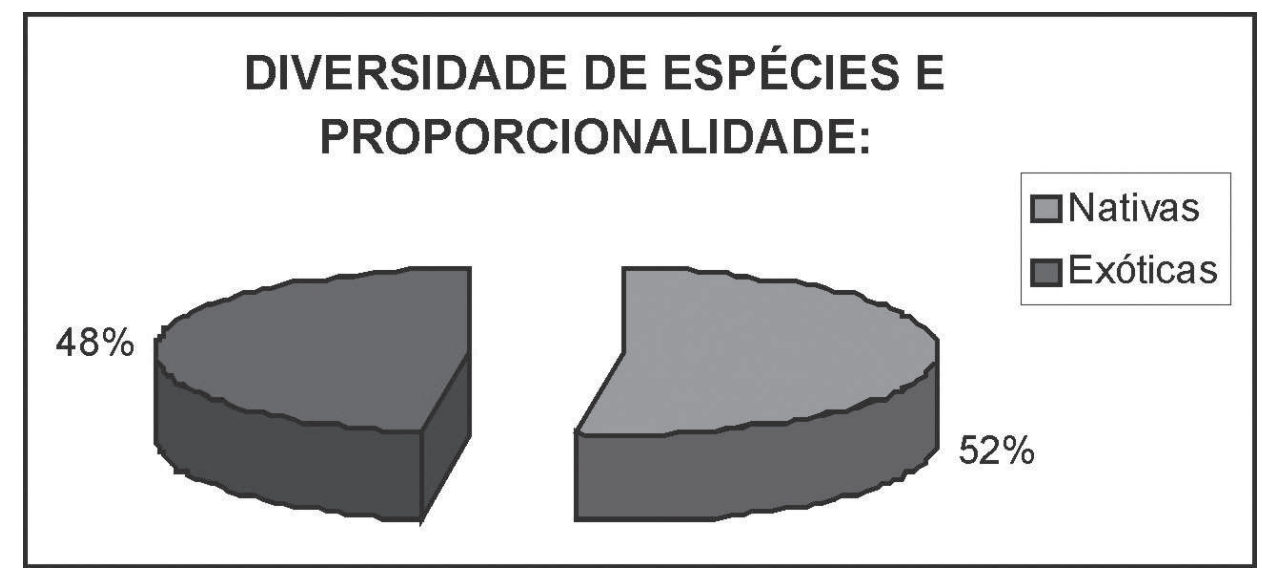

Figura 9: Proporcionalidade de espécies nativas e exóticas do Setor 1 da avenida Afonso Pena, Lagoa Vermelha, RS, 2003

Fonte: Autores

Além de identificar as espécies nativas das exóticas, precisa-se divulgar quais são as espécies alergógenas para que sejam evitadas. No canteiro central da avenida Afonso Pena foram identificadas no canteiro 4 (Figura 10) um total de 62\% de ciprestes (Cupressus sp) e no canteiro 11 um total de $57,6 \%$ de ligustro (Ligustrum japonicum), espécies estas causadoras das chamadas 
polinoses, cuja característica primordial reside no caráter estacional dos sintomas que na realidade só aparecem na época da floração das plantas alergógenas e daí o caráter sazonal das polinoses.

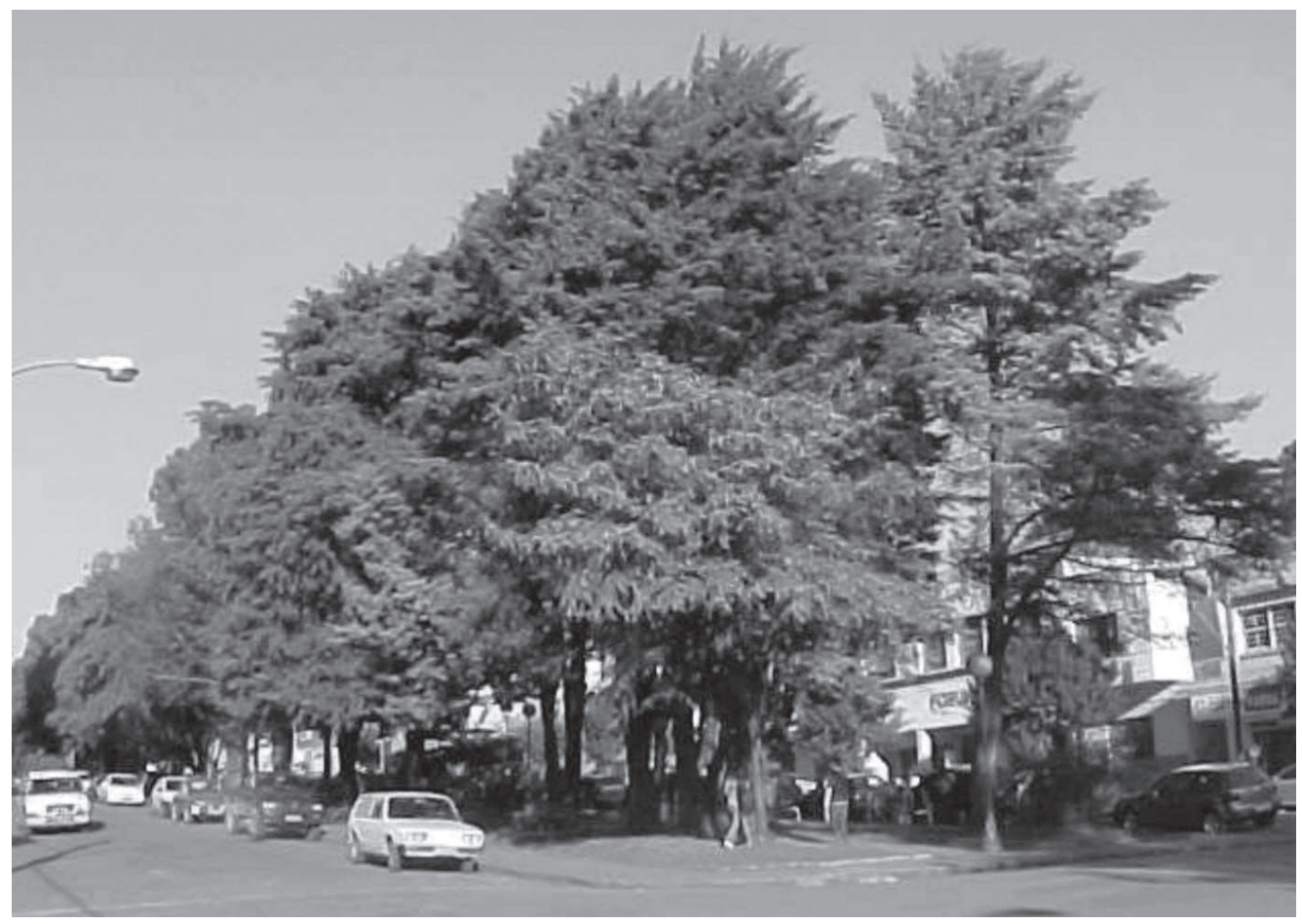

Figura 10. Canteiro com ciprestes da avenida Afonso Pena, Lagoa Vermelha, RS, 2003 Fonte: Autores

A Figura 11 demonstra um quase total fechamento deste espaço, pelo uso do ligustro (Ligustrum japonicum). Quando visualizado do entorno, observa-se o uso exagerado desses exemplares globosos, de folhagem escura, que se traduz em sombreamento do local, e pela tonalidade de suas folhas torna o ambiente escuro, diminuindo a expressão cromática do ambiente. Outro importante fator do ponto de vista estético, é o pouco florescimento de outro tipo de vegetação, questões estas que apontam a necessidade de redução dos ligustros em função de riscos à saúde pública.

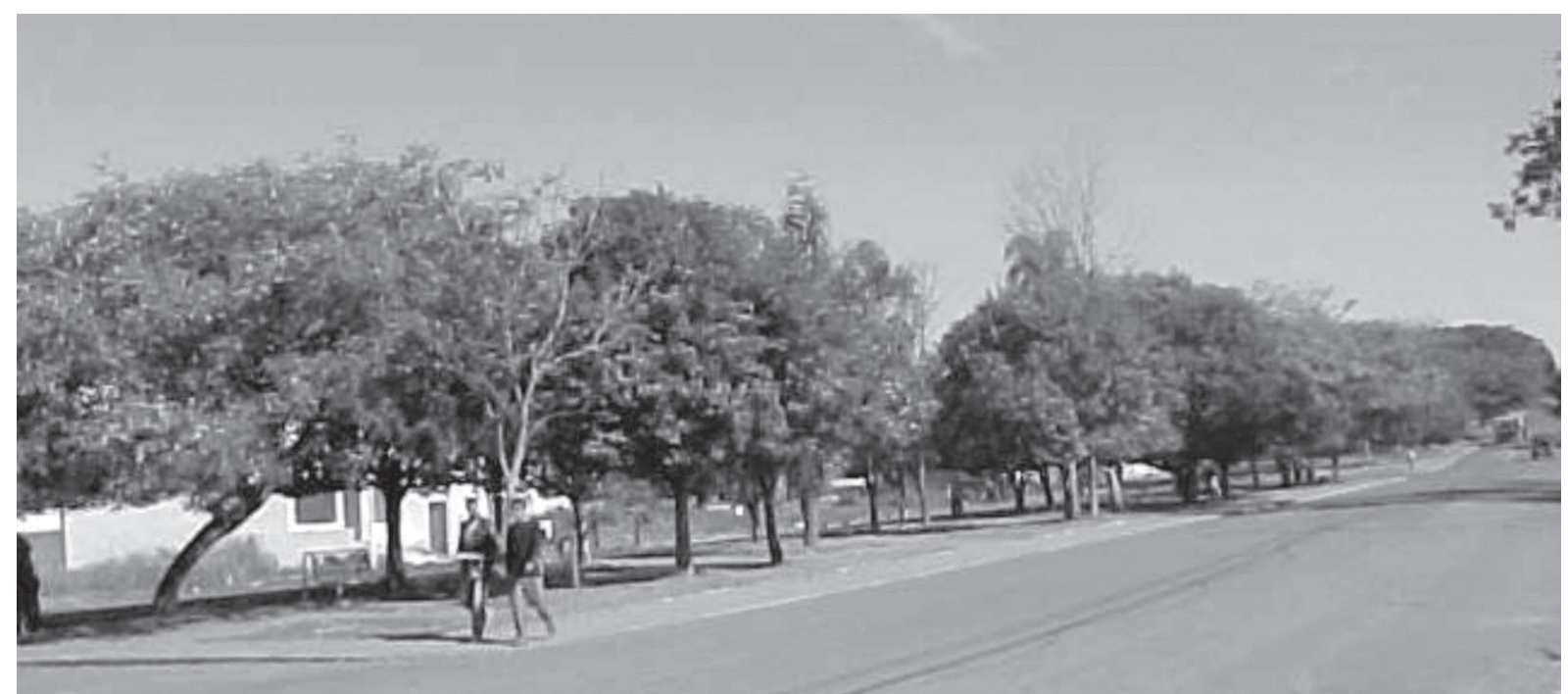

Figura 11: Canteiro com ligustros da avenida Afonso Pena, Lagoa Vermelha, RS, 2003 Fonte: Autores 
O ligustro tem facilidade de adaptação e ampla utilização encontrando-se na arborização de diversos estados brasileiros, como na cidade de Vinhedo, SP, com 16\% na composição da arborização (HANDER, 2002) e na cidade de Curitiba, PR, representava 14,7\% da população arbórea (MILANO, 1987), já na avenida Afonso Pena, em Lagoa Vermelha representa 5\%.

Percebe-se portanto, que a arborização está diretamente relacionada com a qualidade de vida das pessoas, com o aumento da biodiversidade, com a preservação das espécies e também com o bem estar físico e psíquico do ser humano, representando a persistência do elemento natural dentro da estrutura urbana, decorrência e realização do processo cultural cujo desenvolvimento é a característica marcante da evolução humana. Se o plantio de árvores e sua conservação forem feitos de forma adequados todos terão benefícios. $\bigcirc$ planejamento vai muito além da questão técnica, os fatores políticos, legais, sociais e culturais não podem ser negligenciados. É fundamental que a escolha das espécies a serem plantadas seja feita de maneira criteriosa a fim de evitar problemas na rede elétrica, nas redes de água e esgoto, calçamento das ruas, circulação de pedestres e veículos, além de danos a muros e construções em geral.

Lamas, 1992, comenta a respeito da destruição de uma rua histórica em Lisboa, pela retirada das árvores para aumento da faixa de circulação de veículos. O seu aspecto e forma mudaram o desenho arquitetônico, pois a árvore se encontra na mesma escala de valores que a parede, a fachada ou outro elemento construtivo. Um traçado pode ser definido tanto por um alinhamento de árvores como por um alinhamento de edifícios, assim como uma praça. A arquitetura de intenção estética tanto nas estruturas rurais como nas urbanas, tanto no jardim como na cidade. $O$ desenho do espaço não tem duas áreas ou níveis de trabalho - o do edificado e o das estruturas verdes. São ambos elementos da mesma atuação, porventura exigindo alguns conhecimentos disciplinares diferenciados. Assim a retirada da vegetação em alguns pontos da avenida Afonso Pena em Lagoa Vermelha foi estudada de forma criteriosa, sendo retirada somente as espécies arbóreas com comprometimento fitossanitário (Figura 12) ou nos pontos críticos onde comprometia as perspectivas visuais.

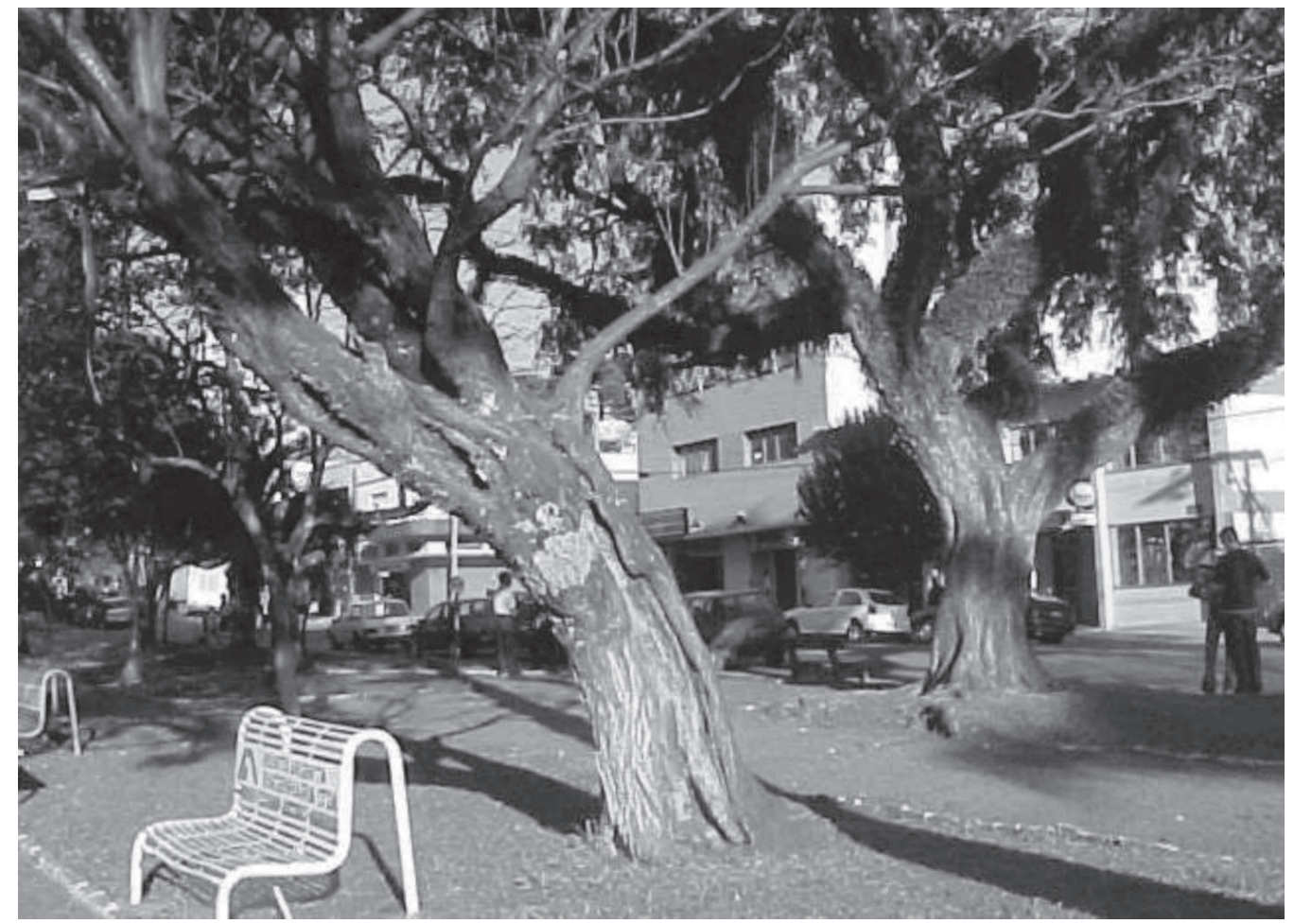

Figura 12: Problemas fitossanitários que comprometem a vegetação da avenida Afonso Pena, Lagoa Vermelha, RS, 2003

Fonte: Autores 
Em níveis sócio-cultural e de conforto psicológico o homem necessita se identificar com um território e um grupo social imediatos à sua residência. Toda cidade deve ser um conjunto perceptível das partes conformando um todo coerente. Cada parte, cada bairro, cada comunidade, com sua identidade própria, sua história e suas características (DEL RIO, 1990). Baseando-se nas colocações sobre a importância da população identificar-se com o local, podem-se referenciar os canteiros da avenida como parte da identidade desta comunidade.

Além da função paisagística, a arborização urbana proporciona benefícios à população como:

a. Proteção contra ventos;

b. diminuição da polvição sonora;

c. absorção de parte dos raios solares;

d. sombreamento;

e. ambientação a pássaros;

f. absorção da polvição atmosférica, neutralizando os seus efeitos na população.

Em função destas premissas é que o planejamento paisagístico urbano deve ser encarado como ação básica, tanto quanto as demais supracitadas. Assim, verifica-se que a implantação dos canteiros centrais da avenida Afonso Pena, ocorreu sem estudo prévio da arborização, sendo necessário realizar planejamento e monitoramento das espécies vegetais de forma a contribuir para a qualidade visual do ambiente construído em relação ao meio ambiente, proporcionando maior qualidade ambiental à área. A maioria das pessoas não entende a íntima relação entre as atividades humanas e o ambiente. É de importância fundamental sensibilizar as pessoas e envolvê-las nos problemas ambientais, no sentido de buscar soluções efetivas para o desenvolvimento e planejamento ambiental (SATO e SANTOS, 1999).

Portanto, o tratamento paisagístico da avenida Afonso Pena, teve por objetivo principal a melhoria de sua qualidade visual e ambiental. A composição da vegetação adotada no projeto, valoriza e potencializa o uso da área (Figura 13). $O$ tratamento inclui o desenho dos espaços abertos e dos acessos. Assim, a área receberá iluminação, pisos, bancos, e outros componentes que somados à vegetação possibilitem a ambientação dos espaços.

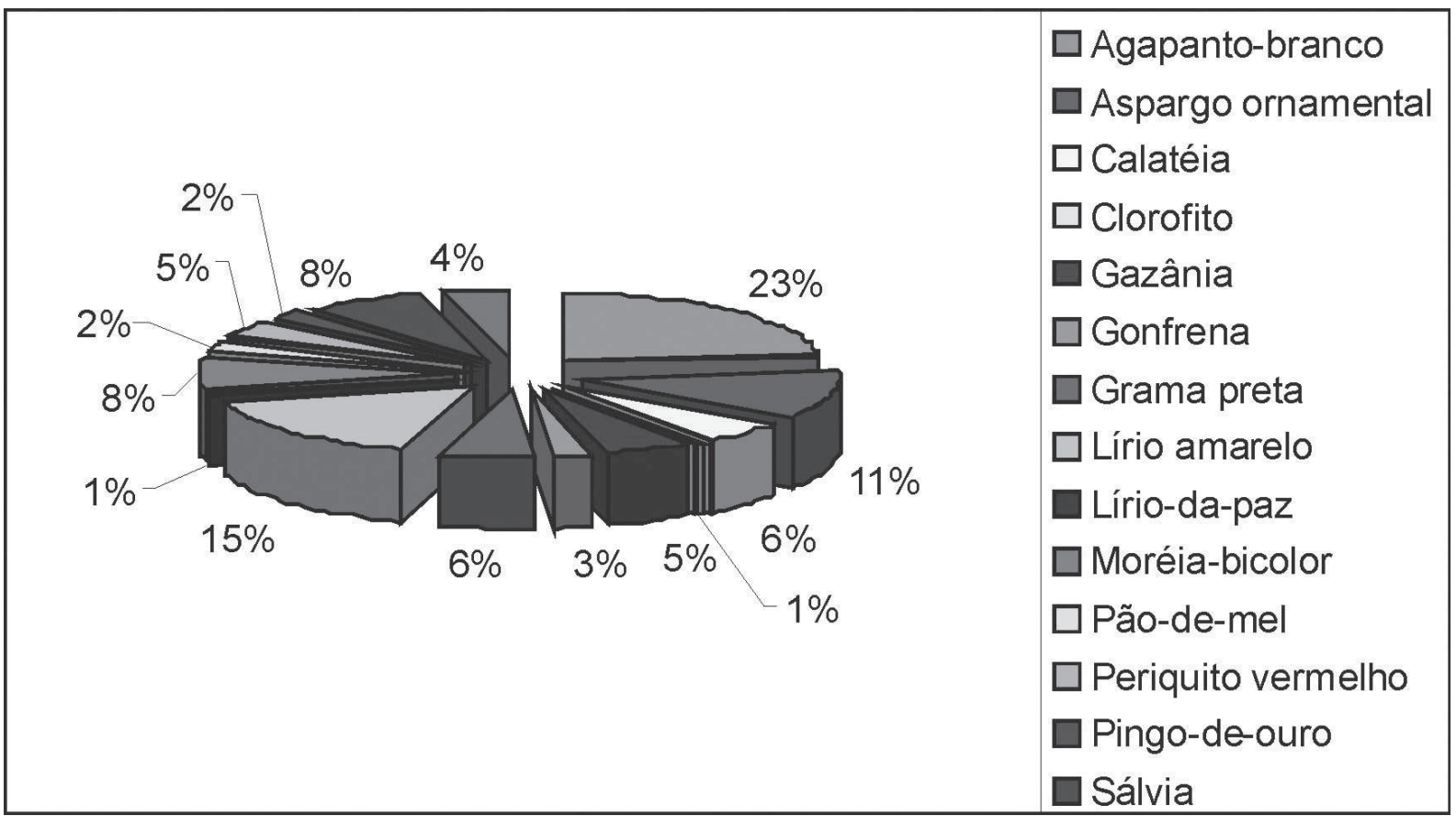

Figura 13: Flores inseridas nos canteiros centrais da avenida Afonso Pena, Lagoa Vermelha, RS, 2003

Fonte: Autores 
A vegetação selecionada e inserida nos canteiros da avenida Afonso Pena têm características botânicas apropriadas às situações e exigências típicas dos canteiros centrais, com potencial ornamental associado à rusticidade e simplicidade na sua manutenção. Composta por espécies arbóreas nativas (Figura 14), com floração variada, monumentalidade e preservação das espécies, seguindo os condicionantes do projeto, as orientações do plano de arborização, a valorização e a preservação da biodiversidade.

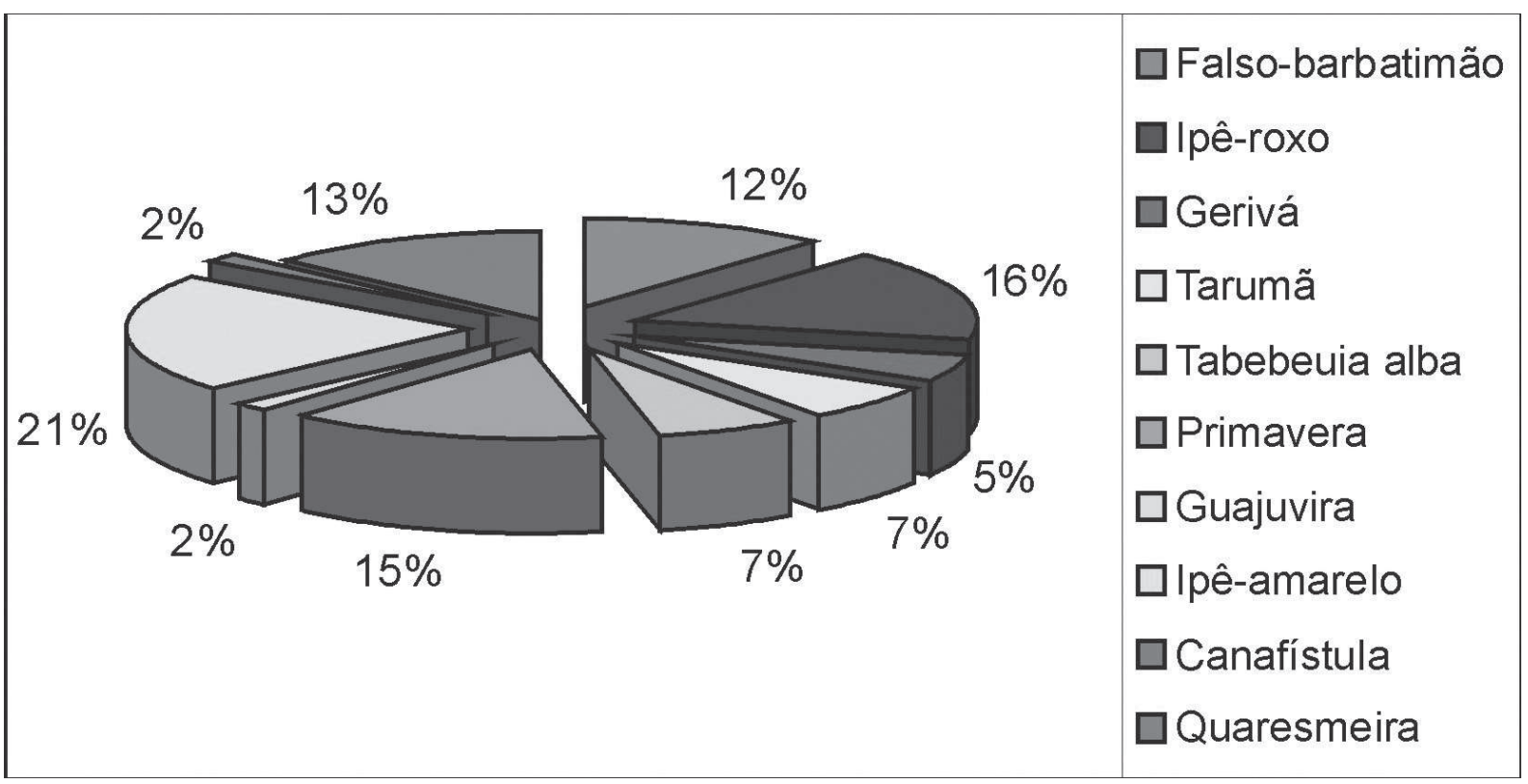

Figura 14: Árvores inseridas nos canteiros centrais da avenida Afonso Pena, Lagoa Vermelha, RS, 2003 Fonte: Autores

O desenvolvimento de qualquer paisagem pode ocorrer pela concentração de suas características paisagísticas naturais, pela integração entre a natureza e a parte projetada ou pela criação de um complexo inteiramente construído. Em qualquer situação, o que se deseja é uma perfeita resolução entre todos os elementos, obtendo-se uma paisagem unificada e equilibrada dinamicamente (KATO, 1993).

A responsabilidade social de um município perpassa por diversos setores entre eles a arborização urbana. Com o objetivo de requalificação urbana e paisagística do Canteiro Central da avenida Afonso Pena, em Lagoa Vermelha-RS visou-se conciliar as esferas econômicas, ambiental e social na geração de um cenário auto-sustentável. Foi realizado o diagnóstico urbano, a composição arbórea e da educação ambiental. Elaborou-se uma proposta paisagística visando à educação ambiental, com responsabilidade social e respeito ao ecodesenvolvimento. Com esta proposta verifica-se a sensibilização e comprometimento dos usuários com a arborização urbana da avenida Afonso Pena. Tal comprometimento viabilizou-se através da educação ambiental com responsabilidade social do poder público municipal e dos diversos segmentos da comunidade, aliado ao desenvolvimento social, ético, econômico e cultural, não se desviando da ótica local para aproveitamento do potencial inerente da região propiciando melhor qualidade de vida, objetivando que a partir disso ocorram mudanças de paradigmas e uma nova postura em relação a situações que envolvem o ambiente como um todo: saneamento básico, destino de resíduos sólidos e polvição visual no âmbito da paisagem urbana.

Através do trabalho realizado no canteiro central da avenida Afonso Pena conclui-se que a maioria das pessoas não entende a íntima relação entre as atividades humanas e o ambiente, por falta de cultura ou informação inadequada. É de importância fundamental sensibilizar as pessoas e envolvê-las nos problemas ambientais, desta forma, as pesquisas podem ser divulgadas em 
eventos científicos pelos autores servindo de referência, no sentido de buscar soluções efetivas para o desenvolvimento e planejamento ambiental.

A composição paisagística adotada no projeto paisagístico buscou valorizar e potencializar o uso da área. Assim, a área recebeu iluminação, pisos, bancos e outros componentes que somados à vegetação possibilitaram a ambientação dos espaços.

Sabe-se que o êxito da implantação e a consolidação dependem de um trabalho de médio e longo prazo, envolvendo e sensibilizando os diversos agentes que atuam na própria comunidade. O comprometimento dos diversos segmentos da comunidade, aliado ao desenvolvimento social, ético, econômico e cultural, voltado para o aproveitamento do potencial inerente da região propiciando melhor qualidade de vida, vislumbram mudanças de paradigmas e uma nova postura em relação a situações que envolvem o ambiente como um todo: saneamento básico, disposição de resíduos sólidos e polvição visual no âmbito da paisagem urbana.

\section{Bibliografia}

CUNHA, G. R. Meteorologia: Fatos \& mitos. Passo Fundo: Embrapa Trigo, 1997. 267p.

DEL RIO, Vicente. Introdução ao desenho urbano no processo de planejamento. São Paulo: Pini, 1990.

HANDER, I. C. F. Inventário quali-quantitativo da arborização e infra-estrutura das praças da cidade de Vinhedo-SP. 2002. 122p. Dissertação (Mestrado) - Escola Superior de Agricultura Luiz de Queiros, Piracicaba, 2002.

KATO, Akinori. Plazas of southern Europe. Tokio: Process Architecture, 1993.

LAMAS, José M. Resseano Garcia. Morfologia urbana e desenho da cidade. Fund Calouste Gulbenkan, 1992. 564p.

LONGHI, R. A. Livro das árvores: Árvores do sul do Brasil. Porto Alegre: L\&PM, 1995. 176p.

LORENZI, H. Árvores brasileiras. Nova Odessa: Ed. Plantarum, 1992. 352p.

MILANO, M. S. O planejamento e o replanejamento da arborização de ruas. In: ENCONTRO NACIONAL DE ARBORIZAÇÃO URBANA, 2, 1987. Maringá. Anais... Maringá: PMM, 1987. p. 1-8.

REITZ, R.; KLEIN, R. M.; REIS, A. Projeto madeira do Rio Grande do Sul. Porto Alegre: Herbário Barbosa Rodrigues e Secretaria da Agricultura do Rio Grande do Sul, 1988. 525p.

SATO, Michele; SANTOS, José Eduardo. Agenda 21: Em sinopse. São Carlos: EdUFSCar, 1999.

SIMÕES JÚNIOR, José Geraldo. Revitalização de centros urbanos. Polis, n. 19, 1994, 73p. 